\section{LA EVOLUCIÓN DEL DERECHO A LA EDUCACIÓN EN COLOMBIA ENTRE 1820 A 1876, COMO UN DERECHO ECONÓMICO, SOCIAL Y CULTURAL*}

\author{
Andrés González Serrano** \\ Universidad Militar Nueva Granada
}

Fecha de recepción: 11 septiembre de 2009

Fecha de aprobación: 15 de octubre de 2009

\section{Resumen}

Al examinar la evolución del derecho a la educación en la Nueva Granada, la Gran Colombia y los Estados Unidos de Colombia, se evidencia un importante esfuerzo por parte de Francisco de Paula Santander y Mariano Ospina Rodríguez de promover el desarrollo de la educación como un derecho que debía ser gratuito y obligatorio.

Sin embargo, el proyecto iniciado por Santander y Ospina Rodríguez y demás presidentes de la época comprendida entre 1820 a 1876, tiene como obstáculo los problemas sociales, políticos, culturales y las guerras civiles que tenían como fin la búsqueda de la autonomía, libertad e independencia.

* El presente trabajo es producto de la línea de Derechos Humanos y Derecho Internacional Humanitario del Grupo de Derecho Público de la Universidad Militar Nueva Granada, que de forma conjunta con la Universidad Libre, Medellín y Manizales está desarrollando el macro proyecto "Evolución Constitucional de los Derechos Humanos en el Bicentenario Constitucional 1810 a 2010". andres.gonzalez@unimilitar.edu.co

** Docente Investigador de planta del Centro de Investigaciones de la Facultad de Derecho de la Universidad Militar Nueva Granada, línea de Derechos Humanos y Derecho Internacional Humanitario del Grupo de Derecho Público. Abogado Magna Cum Laude de la Universidad Militar Nueva Granada. Dirección: Cr. $11 \mathrm{~N}^{\circ}$ 101-80. Conmutador: 2757300 Ext. 262. Bogotá, DC.

\section{Palabras clave}

Historia - Derechos sociales - Educación y Mujer.

\section{THE EVOLUTION OF THE RIGHT TO EDUCATION IN COLOMBIA FROM 1820 TO 1876, AS AN ECONOMIC, SOCIAL AND CULTURAL}

\begin{abstract}
In examining the evolution of the right to education in New Granada, Gran Colombia and the United States of Colombia, a major effort is evidenced by Francisco de Paula Santander, Mariano Ospina Rodriguez to promote the development of education as a right which should be free and compulsory.

However, the project initiated by Santander Ospina Rodriguez and other presidents of the period covered from 1820 to 1876 , is to prevent the social, political, cultural and civil wars that were designed to search for autonomy, freedom and independence.
\end{abstract}

\section{Key words}

History - Social rights - Education and Women

\section{INTRODUCCIÓN}

Dentro del proyecto se establece como pregunta problema: ¿cómo es que se ha estructurado el constitucionalismo colombiano en estos dos siglos de historia institucional $(1810-2010)$ ? Como apoyo para el desarrollo de esta pregunta, el presente producto se circunscribe a identificar, describir y analizar cuál ha sido la evolución del derecho a la educación en el periodo comprendido entre 1820 a 1876.

Para poder solucionar el interrogante planteado, se hace uso del método descriptivo y analítico, centrado en el derecho a la educación como un derecho social, que será analizado y 
descrito con base en la legislación del periodo enunciado, así como el contexto político y social.

El estudio tendrá diferentes etapas, primero consistirá en la recolección de la información, para tal efecto se revisaran las diferentes constituciones, legislación y textos de investigación que hagan remisión directa a la época a analizar y describir. Posteriormente se deberá organizar la información por los periodos a describir que son: periodo fundacional, granadino y federal, por último se analizara y describirá cual ha sido la evolución del derecho a la educación como un derecho social.

\section{EVOLUCIÓN DEL DERECHO A LA EDUCACIÓN EN COLOMBIA}

En este apartado se analizará la evolución del derecho a la educación desde 1820 hasta 1876, para ello se tendrá en cuenta el desarrollo constitucional así como su evolución legislativa y el ideal político del presidente de turno, así como la influencia de la iglesia en la educación.

El primer referente a analizar después de la consolidación de la independencia, es el Congreso General reunido en la ciudad de Cúcuta en 1821 que expidió la llamada Constitución de Cúcuta. La cual fue el reflejo de la independencia y estableció que la soberanía residía en la Nación ${ }^{1}$. En sus disposiciones referentes a la educación se señala que para poder votar en las asambleas parroquiales deberá ser requisito saber leer y escribir, requisito valido solo hasta el año de 1840. En su artículo 55 numeral 19, se establecen las atribuciones especiales del Congreso de, "Promover por leyes la educación pública y el progreso de las ciencias, las artes y los establecimientos útiles, $y$ conceder por tiempo limitado derechos

YOUNES MORENO, Diego. Breve Historia del Derecho Constitucional Colombiano. Bogotá: Legis S.A. 1997. Pág. 27. exclusivos para su estímulo y fomento", por lo que se observa que en esta Constitución el desarrollo que se le dio al derecho a la educación era escaso, pero sería el Congreso que de manera activa tendría mediante la legislación establecer las disposiciones necesarias para que todos los ciudadanos tuvieran acceso a los establecimientos educativos.

Simón Bolívar como presidente de la Gran Colombia $^{3}$, en su gobierno el cual tuvo dos periodos establecidos en el año de 1819 y entre los años de 1827 y 1830, la educación era tema esencial para su gobierno. Sus diversos estudios, sus viajes y el contacto con los eclesiásticos, hicieron que respetara la Iglesia y así estableció como modelo la educación cristiana. En esta época se observaba que quienes podían tener acceso a la educación era la población privilegiada, por lo que una importante cantidad de personas quedaban excluidas de ella. E1 no acceso a la educación por parte de toda la población era un problema que Simón Bolívar entendió que lo que se estaba generando era desigualdad, por lo cual lucho para cambiar esta situación. Así, se estableció la instrucción popular la cual se dividiría en tres instancias primario, medio y universitario. En cooperación con las demás instancias gubernamentales se crearon nuevos colegios donde era fundamental la enseñanza de materias como la escritura, la aritmética y la gramática. Las ideas sobre la educación de Bolívar tenían sustento en la concepción de Robespierre ${ }^{4}$, quien pensaba que la

2 Constitución del 30 de agosto de 1821.

3 Es el nombre dado por el Congreso reunido en la ciudad de Cúcuta a la unión del Virreinato de la Nueva Granada, Venezuela y Quito.

4 Maximilien de Robespierre fue político y revolucionario francés. Tras graduarse en derecho en París, en 1781, ejerció la abogacía. Afín a las ideas liberales y al pensamiento de Rousseau, criticó el sistema judicial y el absolutismo monárquico y abogó por los principios de libertad, igualdad y fraternidad. En abril de 1789 fue elegido diputado por el tercer estado de Artois en los Estados Generales. Defendió la concesión de los 
educación debía ser igual para todos y además deben impartirse en escuelas sostenidas por el Estado y para cubrir la educación de los niños de 6 a 12 años.

Como vicepresidente el General Santander $^{5}$, dicto el decreto de 2 de Junio de 1820, mediante el cual se enfatizo que la educación es un elemento esencial en el desarrollo integral de los ciudadanos. En este decreto se estableció que "el patronato, dirección y gobierno de los colegios de estudios y educación de la República" pertenecían al gobierno, por lo cual la planta de administrativos y docentes se convirtieron en funcionarios públicos. Manifestaba que era fundamental una educación donde se cultivaran las cualidades de cada uno y ocultar los defectos, su sueño era que los ciudadanos ejercieran sus derechos civiles.

Santander trabajando para plasmar las ideas del presidente Simón Bolívar sobre la importancia de la educación y de la necesidad que todos los ciudadanos tuvieran acceso a la instrucción pública, emitió el decreto del 6 de octubre de 1820, donde se estableció que las ciudades, villas y lugares debían tener una escuela pública.

derechos políticos a todos los ciudadanos, el sufragio universal y directo, las libertades de prensa y reunión, la educación gratuita y obligatoria y la abolición de la esclavitud y de la pena de muerte.

$5 \quad$ Francisco de Paula Santander: Fue uno de los jefes de la campaña libertadora que culminó en las batallas del Pantano de Vargas y Boyacá. Nombrado por Bolívar Vicepresidente provisional de Colombia, fue confirmado en este cargo por el Congreso de Cúcuta en 1821. Mientras Bolívar, presidente, hacia la campaña del Sur, Santander ejerció el poder ejecutivo hasta 1827. Acusado de complicidad en la conspiración del 25 de septiembre contra la vida del Libertador, fue condenado a muerte. Conmutada su pena por el destierro, residió en Europa desde 1829, después de haber estado prisionero en Cartagena. Viajó por Inglaterra, Francia y Alemania. Elegido presidente en 1832, al disolverse la Gran Colombia, regresó al país y ejerció la primera magistratura hasta 1837 . Elegido miembro del Congreso Nacional intervino muy activamente en la política nacional como jefe de la oposición al presidente Marques. Al morir tenía 48 años de edad.
Los conventos religiosos debían sostener una escuela pública con maestros que designara el Prelado. Las parroquias y pueblos que contaran con los treinta vecinos crearan un instituto. Este decreto se constituyó como el primer plan de instrucción primaria, donde se señalaba que materias se debían impartir a los estudiantes y que serviría para su desarrollo como ciudadano. Además se le indica a la Iglesia que debía colaborar en la educación de los ciudadanos, así todas las instancias se esforzarían para cumplir con los postulados de la instrucción pública.

Para el año de 1821, se realizo el Congreso de Cúcuta $^{6}$ donde uno de sus pronunciamientos fue respecto al establecimiento de escuelas para niñas en los conventos y creación de escuelas de primeras letras. Como medida se estableció en el Congreso de Cúcuta, la creación en el territorio escuelas normales que seguían el método Lancasteriano, tomado del educador José Lancaster, quien de manera autodidacta fundó una escuela primaria en 1798 en Southwark (Londres), donde proporcionaba instrucción gratuita a niños varones de escasos recursos, se valía de alumnos especialmente seleccionados para servir de monitores en la educación de sus condiscípulos. El método fue conocido como enseñanza Mutua o sistema Lancasteriano. Mediante escritos y conferencias públicas, despertó en todo el territorio de las islas británicas gran interés por la causa de la instrucción popular para niños y niñas. Él fue el primero en instituir programas de entrenamiento para la formación de maestros. Lancaster insistía en que se excluyera del programa de enseñanza cualquier dogma religioso, pero al mismo tiempo se recurría al uso de pasajes bíblicos

$6 \quad$ El Congreso de Cúcuta fue una asamblea donde se redactó y aprobó la Constitución de Cúcuta, carta magna que dio origen a la Gran Colombia. Fue instaurada por Antonio Nariño ${ }^{1}$ y en ella participaron Simón Bolívar, Francisco de Paula Santander y otros importantes próceres de la independencia. Inició el 30 de agosto de 1821 y culminó el 3 de octubre del mismo año. 
para las prácticas de lectura, sin comentario ni anotaciones ${ }^{7}$. Su sistema fue introducido por fray Sebastián de Mora, quien lo aprendió en la península ibérica y estableció la primera escuela Lancasteriana en América, fue el general Santander quien lo trajo para que fundara la primera escuela Mutua y el gobierno le confirió la dirección de la primera escuela normal ${ }^{8}$. Este sistema fue novedoso en la educación que se impartía en las escuelas, era fundamental la moral como elemento integrante de los planes de estudio, pero se excluía el aspecto religioso, porque para este nuevo sistema era importante que el estudiante escogiera que religión deseaba practicar.

Bajo el gobierno de Santander fue expedida la Ley del 6 de agosto de 1821, mediante la cual se indicó que los conventos menores serian destinados para colegios o casas de educación, si al momento de la sanción de la ley no tenía mas de 8 religiosos. Además se emitió la Ley 2 de 1821, donde las mujeres en este caso las niñas tuvieron acceso a la educación, la cual se impartiría en los conventos de religiosas y sobre colegios y casas de educación. En 1822 se crearon colegios en Tunja por decreto del 17 de mayo y Medellín por el 9 de octubre y se creó la escuela de Puente Nacional. E1 21 de diciembre del mismo año se creo el colegio de San Simón de Ibagué y se restableció el de Popayán. La ley fundamental de Cúcuta, constituía lectura semanal obligatoria en todas las escuelas y colegios $^{9}$, para conservar las buenas costumbres que primaban en la sociedad se prohibió el comercio de libros obscenos.

En la misma década del veinte el General Santander expide el decreto 1 de $1826^{10}$, estable-

\footnotetext{
http://www.ivic.ve/memoria/bios/lancaster_joseph. htm

8 BOHÓRQUEZ, Op. Cit., p.265.

9 BOHÓRQUEZ, Op. Cit., p.243.
}

10 Decreto 1 de 1826: Artículo 14. Además de lo que ha de enseñarse en las escuelas parroquiales, se enseñarán ciendo el "plan de estudios" que debían observar las escuelas. Las materias que se desarrollarían eran fundamentalmente la lectura, escritura, lecciones de moral, urbanidad, gramática y ortografía, aritmética y geografía. De la misma forma para promover la educación en todos los niveles, no sólo se hicieron esfuerzos de crear planteles educativos para el nivel de primaria y bachillerato, por lo cual se implementaron medidas legislativas que cubriera el nivel universitario, es así como con el decreto del $10 \mathrm{de}$ mayo de 1824, se creó la Universidad de Trujillo en el Perú, el 25 de diciembre de 1826 se inauguró la Universidad Central de Bogotá en la Iglesia de San Carlos y con el decreto del 6 de Noviembre de 1827 se dio inicio a la Universidad de Quito. Era esencial para el gobierno que en los planes de estudio de las universidades las cátedras se rigieran por medio de principios morales, ello como parte del desarrollo integral del estudiante.

Otra medida que se promovió para que el derecho a la instrucción pública se desarrollara de manera eficaz, fue instituir como obligación para los padres llevar a sus hijos a las escuelas y dejarlos allí hasta que aprendieran a leer y a escribir. Si los padres no permitían que sus hijos recibieran educación serian acreedores de sanciones. Así se estableció en el decreto promulgado el 5 de diciembre de 1829. Lo cual presento inconvenientes, ya que muchas familias residían muy lejos del lugar donde se encontraba la escuela, dificultando que

\footnotetext{
en las que haya en las cabeceras de cantón, compendios más extensos de gramática y ortografía castellana y de geografía, los elementos de aritmética integral, decimal y comercial, que acaban de imprimirse en Bogotá, la cubicación, la agrimensura por medio de triángulos proporcionales; la geometría práctica, por Hijosa; la cartilla de dibujo, impresa para las escuelas de Madrid, el catecismo de industria rural y económica de Mora; y en las cabeceras de cantón donde se pueda y convengan los catecismos de agricultura y de historia moderna del mismo Mora y la de veterinaria.
} 
los padres llevaran a sus hijos a que se les impartiera educación.

Terminada la década de los veinte (1820) y con la llegada de la década del treinta (1830), se da una nueva constitución, la cual consagró de nuevo en su artículo 14, que para gozar los derechos de ciudadano se debía saber leer y escribir, lo cual fue obligatorio hasta el año de 1940 y estableció que el Congreso debería promover por medio de la ley la educación pública en las universidades y colegios nacionales, el progreso de las ciencias y artes ${ }^{11}$, de la misma manera lo señalo la Constitución de $1832^{12}$.

Con la llegada de la década de 1830, el general Santander llega a la presidencia entre 1832 y 1837 y una de sus mayores preocupaciones, fue el desarrollo de un sistema de educación pública para consolidar la República en la Nueva Granada ${ }^{13}$. Las cátedras que estableció el general Santander en los colegios fueron: la cátedra de jurisprudencia, cátedra de filosofía y teología. Sus políticas generaron que en la Gran Colombia se contaran con Universidades en las ciudades principales como Bogotá, Caracas, Quito, con colegios que contaban con facultades y más escuelas públicas. Es importante señalar que Santander conto con ilustres colaboradores, entre los cuales es necesario destacar la labor del señor Rufino Cuervo $^{14}$, uno de los más comprometidos con

\footnotetext{
Constitución del 5 de Mayo de 1830.

12 Constitución del 1 de Marzo de 1832.

13 VALENCIA VILLA, Hernando. Cartas de Batalla Una critica del constitucionalismo colombiano. Bogotá: Fondo Editorial CEREC. 1997. Pág. 91-93.
}

14 Rufino Cuervo: fue un político, abogado y periodista colombiano. Estudió Derecho en el Colegio del Rosario, tras lo cual se vinculó a la actividad pública, inicialmente como funcionario de la secretaría de Hacienda y posteriormente como parlamentario y jefe político de Bogotá. Durante la presidencia de Pedro Alcántara Herrán fue secretario de Hacienda y embajador en Ecuador. Fue candidato a la presidencia de Nueva Granada en 1845, ocupando el tercer lugar; si bien el Congreso, que debía definir la elección al el desarrollo de la educación pública, el cual en el año de 1833 fundo la Sociedad de Educación Primaria. Rufino Cuervo fundó el Colegio de la merced donde se impartía educación religiosa y economía domestica, además se les enseñaban lenguas modernas, gramática y música ${ }^{15}$. El trabajo mancomunado de Santander y Cuervo dio frutos, al señalar en el año de 1833 que se paso de 378 a 1000 escuelas, entre públicas y privadas, y una población escolar de 27.070 estudiantes. En esta época la educación de los hombres era lo principal, pero como un acontecimiento en la educación de las mujeres, se establecieron las primeras escuelas lancasterianas para niñas en los conventos de Santa Inés y Santa Clara.

El desarrollo de la educación para las mujeres fue muy escaso en esta época, pero fue el doctor Rufino Cuervo quien busco que se crearan instituciones para las mujeres, y fue el gestor de la creación del Colegio de la Merced, el cual tenia como fin la educación de las hijas de los próceres de la independencia y familias distinguidas de la patria. Este avance fue acosta de la Iglesia, quienes fueron expropiados de conventos para así crear esta institución.

La política de expropiaciones a las comunidades religiosas, genero la apertura de nuevos colegios y facultades. Lo cual genero que la Iglesia se distanciara del gobierno, ya que los parámetros de la educación de este gobierno eran una educación liberal y laicista. El general causo una gran controversia al ordenar que en los colegios y en las universidades, se dictara el derecho con fundamento en los postulados de

no presentarse una candidatura con mayoría absoluta, lo escogió como vicepresidente, y al general Tomás Cipriano de Mosquera como presidente. Entre el 14 de agosto y el 14 de diciembre de 1847 le correspondió ocupar la presidencia de la república, ante la ausencia del general Mosquera.

15 JARAMILLO, Manual de Historia de Colombia. Op. Cit., p $258-259$. 
Jeremy Bentham ${ }^{16}$, la cual indicaba la libertad de la palabra en el parlamento y en las escuelas públicas, pero fue criticado en cuanto a sus postulados era sus pronunciamientos sobre la filosofía moral, donde el derecho tiene un principio que lo guía y es el de su utilidad ${ }^{17}$. Para establecer si una acción era buena o mala se debía establecer la utilidad de esta acción, el objetivo a lograr por parte de los ciudadanos es la mayor felicidad. La iglesia no compartía que se impartieran en las instituciones educativas esta tipo de postulados ya que consideraban que iba en contra de la religión y de la fe católica.

Sin embargo, Santander aprobó una ley donde consagraba la libertad de enseñanza y se le concede autonomía al Colegio Mayor de Nuestra señora del Rosario que funcionaba como parte de la Universidad Central. Es importante reseñar al Colegio Mayor de Nuestra señora del Rosario, que fue creado el 31 de diciembre de

16 Jeremy Bentham: Sus trabajos iníciales atacando el sistema legal y judicial inglés le llevaron a la formulación de la doctrina utilitarista, plasmada en su obra principal: Introducción a los principios de moral y legislación (1789). En ella preconizaba que todo acto humano, norma o institución, deben ser juzgados según la utilidad que tienen, esto es, según el placer o el sufrimiento que producen en las personas. A partir de esa simplificación de un criterio tan antiguo como el mundo, proponía formalizar el análisis de las cuestiones políticas, sociales y económicas, sobre la base de medir la utilidad de cada acción o decisión. Así se fundamentaría una nueva ética, basada en el goce de la vida y no en el sacrificio ni el sufrimiento. El objetivo último de lograr «la mayor felicidad para el mayor número» le acercó a corrientes políticas progresistas y democráticas: la Francia republicana surgida de la Revolución le honró con el título de «ciudadano honorario» (1792), si bien Bentham discrepaba profundamente del racionalismo de Rousseau y consideraba absurdo el planteamiento iusnaturalista subyacente a la Declaración de Derechos del Hombre y del Ciudadano de 1789. Negaba también la «religión natural», que construía el concepto de Dios por analogía con los soberanos de la tierra, y defendía la «religión revelada».

17 J. G. AHERN, Evelyn. El desarrollo de la educación en Colombia 1820-1850. Bogotá: Universidad Pedagógica Nacional.
1651. El Arzobispo de Torres, formado en la Orden de Predicadores, en principio designó a dos frailes dominicos como Rector y Vicerrector respectivamente pero se reservó el derecho de nombrar a los Colegiales que habrían de cursar Jurisprudencia, Medicina o Teología luego de la formación en Artes o sea Filosofía ${ }^{18}$. Se puede destacar de esta institución el sistema de selección de sus estudiantes ${ }^{19}$, donde era importante la nobleza y limpieza de sangre. Se indagaba por el origen de los apellidos, la condición social y la religión pretendiente. Uno de los requisitos era la igualdad en el matrimonio de los padres, el casamiento de los padres y abuelos debían ser realizados "entre iguales", es decir, entre blancos, lo que determinaba así la alcurnia del colegial. E1 oficio del padre establecía la condición social del colegial. Los oficios más honrados eran los cargos públicos, a medida que paso el tiempo era muy importante los oficios de mercaderes e industriales y los médicos empezaron a gozar de prestigio.

Anteriormente se señaló como se consagra la autonomía de los centros educativos y bajo la línea de gobierno de Santander, para quien la educación es fundamental como formación de los ciudadanos procuro que todas las personas aprendieran a leer y a escribir sin distinción de la clase social, por el anterior postulado la educación debía ser accesible para todos los niveles y así quedo plasmado en sus directrices y se evidenció el incremento de las escuelas y la asistencia de niños de ambos sexos a las escuelas al finalizar su gobierno en 1837.

De otro lado es importante señalar como se implemento la educación en el gobierno del

18 http://www.urosario.edu.co/FASE4/web_visitantes/historia.htm

19 GUILLÉN DE IRIARTE, María Clara. Los estudiantes del Colegio Mayor de Nuestra señora del Rosario. Bogotá: Editorial Universidad del Rosario, 2008. Pág. 60 . 
presidente Pedro Alcántara Herrán ${ }^{20}$ donde el sistema educativo tuvo que enfrentarse a cambios, debido a la crisis social. Por lo cual el Ministro del Interior, Mariano Ospina ${ }^{21}$, reformó el sistema educativo, siendo un gran crítico de la manera como la educación estaba siendo impartida en el país y por ende hubo reformas en las escuelas elementales, en los colegios y las universidades. Es así como se promulga el decreto de 2 de mayo de 1844, que reglamentó la enseñanza primaria y normalista promulgando un Código de instrucción pública de 48 capítulos y 348 artículos. La emisión de estas leyes se realizó bajo el postulado de la intervención del Estado en la educación pública y privada, pero se respeto la libertad de la enseñanza, en este gobierno se le dio la posibilidad que los particulares pudieran abrir establecimientos de estudios, lo que hacia que el acceso a la educación fuera más amplio en el territorio.

20 Pedro Alcántara Herrán: fue un militar y político colombiano. Entre 1821 y 1824, Herrán Zaldúa luchó en la guerra de la independencia a las órdenes del mariscal Antonio José de Sucre, con quien participó en la batalla de Ayacucho, y al que acompañó en los años siguientes durante su gobierno en Bolivia. Posteriormente se dedicó a la política, y ocupó diversos cargos. Como presidente de la República de Nueva Granada (1841-1845), promulgó la Constitución de $1843 \mathrm{y}$, aplicando una política conservadora, suprimió la libertad de prensa y otorgó al clero el monopolio de la educación, además de permitir el retorno de los jesuitas. Dado el alcance de las reformas conservadoras y el papel de la Iglesia en la sociedad, los liberales no tardaron en reaccionar violentamente.

21 Mariano Ospina Rodríguez: fue político, periodista y abogado colombiano, fundador del Partido Conservador, Colombia y Presidente de la República entre 1857 y 1861. Las características de su personalidad eran excelentes por el buen trato a las personas. Alineado al sector ministerial o moderado, fue designado por el Presidente Pedro Alcántara Herrán como secretario de lo Interior y Relaciones Exteriores en 1841; desde este cargo participó activamente en la redacción de la Constitución de 1843 y planteó un férreo sistema para la educación básica y media del país; posteriormente cual ocupó la gobernación de Antioquia.
Se destaca que la educación bajo la directriz del ministro Mariano Ospina se hace énfasis en la enseñanza de las ciencias útiles como la formación moral y la disciplina. El plan de estudios estaba basado en la formación moral, religiosa, urbanidad, la lectura, la elegancia, escritura, gramática y la ortografía, la aritmética y la lengua castellana, la historia de la Nueva granada, agricultura y la económica ${ }^{22}$. En sus señalamientos manifestaba que era muy importante que se implementará la educación técnica, ya que así se satisfacerán otras necesidades que tenia el país. Una de las medidas para desarrollar esta idea, se ordeno que se trajeran maestros extranjeros que enseñaran conocimientos industriales. Fue de gran interés para este ministro la implementación de la enseñanza técnica a los ciudadanos que estuvieran interesados en aprender diferentes oficios.

Para el ministro Ospina era muy importante la colaboración de los Jesuitas en el proceso de educación para todas las personas del país, por lo cual expresó su apoyo a los jesuitas y le expreso al Congreso que seria beneficioso las misiones religiosas, porque así se llegarían a lugares del territorio donde no se cuenta con escuelas. Pero esta idea duro muy poco tiempo, ya que el gobierno debido a las criticas de instancias sociales que ligaban a los jesuitas con el gobierno español, lo cual fue asociado con el miedo a que los españoles colonizaran de nuevo y el efecto fue el contrario y el gobierno tuvo que cerrar las instituciones donde ellos ejercían sus labores y no colaborarles económicamente. Finalizando la década de 1840, sube a la presidencia de la República José Hilario López que ha pesar de haber realizado un compromiso con un padre superior de los jesuitas los expulso del territorio. A consecuencia de cómo vimos anteriormente de presiones por parte de ciudadanos que no los querían en el

22 JARAMILLO URIBE, Jaime. Nueva historia de Colombia. Bogotá: Planeta Colombia Editorial S.A, VOL. 2, 1989. P. 225-227.

Bogotá, D.C. Colombia - Volumen XII - No. 24 - Julio - Diciembre 2009 - ISSN 0121-182X 
territorio. Pero no solo la Compañía de Jesús tenia contradictores, sino también seguidores, que deseaban una educación basada en principios religiosos. Los jesuitas manejaban varios colegios en el territorio, pero la constitución nacional del año $1853^{23}$, estableció la libertad de la iglesia y por consecuencia los jesuitas volvieron al país a seguir con su labor misionera, no solo religiosa sino para impartir educación. Igualmente en la constitución se le impone una obligación al gobierno el cual es que deberían garantizar a los granadinos la instrucción cuando no sea costeada por fondos públicos.

Sin embargo en la década de 1850 el antiguo ministro de interior Mariano Ospina llega a la presidencia en el año de 1857 y desarrolla aun más su concepción sobre la educación. Es así como en su gobierno se promovieron jardines infantiles, talleres y la educación técnica, esta como mecanismo para resolver problemas de los ciudadanos y del país. También se crearon escuelas rurales, donde se promovía el cultivo de árboles y plantas, al finalizar clases los niños recibían semillas, para que cultivara en su casa y fuera beneficio para la familia ${ }^{24}$. Tristemente estas ideas y políticas de gobierno, eran avanzadas para la época y soportó críticas por parte de Tomas Cipriano de Mosquera ${ }^{25}$, el cual deseaba gobernar autónomamente y como era obvio el presidente Ospina defendía la autoridad central. Esta situación no permitió que los esfuerzos de Ospina para implementar la educación en todo el territorio y en todos los niveles se desarrollara de la manera que el deseaba. Pero como fin de su gobierno, Tomas Cipriano de Mosquera lo derroco y fue exiliado a Guatemala.

23 Constitución de la República de Nueva Granada de 1853.

24 BOHÓRQUEZ, Op. Cit., p. 341.

25 Tomás Cipriano de Mosquera: militar, político, reformador y diplomático colombiano, que se desempeñó como Presidente de la Nueva Granada entre 1845 y 1849 y de los Estados Unidos de Colombia entre 1861 y 1864 y de 1866 a 1867.
A su turno, el general Tomas Cipriano de Mosquera trato de impulsar la educación y como él estableció sanar los desordenes que provoco la ley de 1850 sobre la libertad de enseñanza, estableció que ningún sacerdote podría ejercer su ministerio sin permiso del gobierno general, so pena de destierro del territorio, lo cual generó que la Compañía de Jesús saliera del país y que el gobierno tomara posesión de todos sus bienes $^{26}$. Pero las disposiciones de este gobierno no sólo afecto a los jesuitas sino también a las demás corporaciones o comunidades religiosas que sufrieron un proceso de expropiación de sus bienes al gobierno.

Sin embargo se debe al gobierno de Tomas Cipriano de Mosquera la creación por ley 66 de 22 de septiembre de 1867 el nacimiento de la Universidad Nacional. El estatuto orgánico de la Universidad Nacional fue 265 artículos, señalando en su articulo 1 "La Universidad Nacional se compondrá de las siguientes escuelas y en ellas dará enseñanza publica y gratuita a todos los que la soliciten, sometiéndose a los reglamentos contenidos en el presente decreto: Literatura y filosofía; Ingeniería Civil y Militar; Ciencias Naturales; Artes y oficios; Medicina; y Jurisprudencia ${ }^{27}$. En su artículo 2 se indicaba que la inspección y el gobierno de la Universidad estará a cargo del Secretario del interior, que es el Director General de la Instrucción Universitaria, de un Gran Consejo, de una Junta de Inspección, del Rector de la universidad y de los rectores y Consejos de las escuelas ${ }^{28}$. Pero la universidad Nacional no pudo desarrollar sus políticas libremente, se podía verificar y como lo consta es su estatuto, que en las directivas había presencia del gobierno, los cuales se encargaban de establecer cual era la filosofía

${ }_{26}$ BOHÓRQUEZ, Op. Cit., p. 342.

27 http://www.unal.edu.co/documentos/creacion_ unal.pdf

28 SUESCÚN MONROY, Eduardo. Universidad Proceso histórico y jurídico. Bogotá: Editorial Grijalbo S.A. 1994. Pág. 45-58. 
que debía seguir la Universidad, y mediante el estudio de las ciencias sociales y el derecho público, se deseaba que los estudiantes siguieran creyendo en los parámetros establecidos por los republicanos.

Dando un salto a la década de 1870 , se debe de resaltar la reforma educativa de 1870. La cual fué desarrollada en el gobierno del general Eustorgio Salgar ${ }^{29}$ con el apoyo del secretario del Interior Felipe Zapata. Esta reforma se inspiro en lo establecido por la Constitución de 1863, donde se estableció que la escuela pública seria obligatoria y gratuita. La reforma abarco todos los niveles de educación primaria, secundaria y la universitaria, es por esto que se les dio prioridad a las escuelas de primeras letras y así se estableció que la escuela seria gratuita y obligatoria. Mediante el decreto orgánico de la instrucción pública primaria del 1 de noviembre de 1870 , autorizaron al gobierno del general Salgar para que reorganizara la institución pública, esta fue la norma en que tenía su sustento la reforma, se establecía los métodos de enseñanza, los sistemas disciplinarios y los ideales morales ${ }^{30}$. El desarrollo de la educación con esta reforma fue amplio y en todos los aspectos, regulándose donde se debían de realizar las clases, quienes deberían ser los maestros y sus calidades y las cátedras que se debían implementar.

De la misma forma la reforma del 1870 estableció una entidad que manejaba la educación

29 General Eustorgio Salgar: Político y militar, presidente de la República entre 1870 y 1872, nacido en Bogotá, el 1 de noviembre de 1831, muerto en la misma ciudad, el 25 de noviembre de 1885. En el período histórico del radicalismo colombiano, al general Eustorgio Salgar Moreno, llamado "el Presidente Caballero", le correspondió gobernar los Estados Unidos de Colombia en unos años de alta cultura nacional y de consolidación de la educación, con la creación de las escuelas normales para la formación de los maestros colombianos.

30 JARAMILLO, Manual de Historia de Colombia. Op. Cit., p. 265. en el país, la cual era la Dirección Nacional de Instrucción Publica, anexa al Ministerio del Interior, encargado del desarrollo de la política educativa y en los Estados Federales se crearon los directores de instrucción pública. También la reforma consagro que los ciudadanos mas ilustres del distrito, se les debían de asignar la función de vigilar a los niños de asistir a la escuela. De esta manera el desarrollo de la educación seria un trabajo del gobierno con colaboración de la sociedad, para realizarse así una participación activa de la ciudadanía que era la más interesada en que sus niños asistieran a las escuelas.

El Estado tenía a cargo las escuelas normales que funcionarían en la capital de cada Estado, los gastos de la inspección nacional y la provisión de los libros y útiles de enseñanza y el sostenimiento de las bibliotecas públicas. En la época de 1870 y con la reforma se avanzo respecto a la educación que se le proporcionaba a la niñez, se manifestó como los distritos debían proporcionar todo lo necesario para que se pudiera acudir a las escuelas, un ejemplo de ello, es que le tenía que proporcionar a los niños los elementos necesarios para que pudieran realizar sus actividades escolares de manera idónea. Las Escuelas se dividían así: primarias; primarias superiores; de niñas; normales nacionales y seccionales y casas de asilo (salas-cunas $\mathrm{u}$ hogares infantiles donde se mantendrían los hijos de las madres que tuviesen que trabajar). El plan de Estudios tenia influencia europea, donde se prohibía los castigos corporales, se prohíbe las preferencias por razones de clase social done el ideal de la educación de esta época era formar ciudadanos virtuosos ${ }^{31}$. La educación se fundaba en la moral y en desarrollo de principios como era el de la verdad, la piedad, la tolerancia, el respeto y amor a su país, la benevolencia, y eran los maestros que

31 JARAMILLO, Manual de Historia de Colombia. $O p$. Cit., p. 266. 
deberían instruir de esta manera a sus estudiantes, y así se constituirá una buena sociedad, que era lo que el gobierno perseguía.

En los anteriores gobiernos y legislaturas se estableció la gratuidad de la educación, pero no la obligatoriedad. Con este plan educativo se impuso una obligación a la persona que tenían a su cargo un niño, debían enviarlos a la escuela, o proporcionarles la instrucción, desde los 7 años hasta los 15 años cumplidos. Una vez cumplido los 15 años es decisión del joven ir a la escuela pero los funcionarios les recomendaran que acudan a la escuela. Al incumplimiento de esta obligación se le impuso una sanción que en casos podría llevar a que los padres perdieran la patria potestad sobre sus hijos y se les designaran tutores y guardadores. Se verifica así que nos encontrábamos en una época que era muy serio que los menores recibieran la instrucción necesaria para a ser un buen ciudadano.

Otro avance de la reforma de 1870, fue la revista denominada "Escuela Normal", donde se publicaron textos de enseñanza, se informaba al público y a los maestros y profesores sobre las directrices oficiales, además sobre el movimiento educativo en el exterior. Se traducían artículos y ensayos sobre temas de ciencias naturales, historia, filosofía y pedagogía ${ }^{32}$. Mediante esta revista se le dio la posibilidad que educadores expusieran su metodología de educación y así otros pudieran aplicarla. Además era una manera de conocer la normatividad de ese tiempo y así se sabría como se podría instruir a la población estudiantil y sobre todo podrían introducir en las metodologías nuevos aspectos culturales y educativos que se gestaban en Europa.

La reforma educativa del 70 era muy optimista en cuanto a la aplicación de sus preceptos como en la implementación de escuelas en todo el

JARAMILLO, Manual de Historia de Colombia Op. Cit., p. 271. territorio, el problema era la falta de recursos económicos, lo cual frustro su esfuerzo. Otro aspecto que influenció en el fracaso de la reforma, fue que la Iglesia con el apoyo de un grupo de creyentes y por la separación con el gobierno, emitió directrices como la excomulgación de las personas que matricularan sus hijos en las escuelas públicas oficiales, esto como consecuencia de lo señalado por el gobierno el cual prohibió que en las escuelas públicas se impartiera la enseñanza religiosa obligatoria, siendo potestativo de la institución si lo imparte o no. Lo cual consideraba la iglesia que iba en contra de la formación católica de los estudiantes y lo que generaría en la sociedad, eran estudiantes con creencias comunistas y la desviación del estudiante en creencias vagas, sin amor por su patria y sin virtudes.

Sumado a lo anterior el desarrollo de la reforma entra en crisis por el desorden político y social, bajo un ambiente de guerra civil, lo cual la interrumpió en su totalidad debido que se decretó el cierre de las universidades por dos años y fueron convertidas en cuarteles ${ }^{33}$.

\section{EL DERECHO A LA EDUCACIÓN DE LAS MUJERES}

La educación pública en la Gran Colombia fue de gran preocupación para Francisco de Paula Santander, debido que durante el siglo XVIII la educación se dedicó de forma casi exclusiva a una minoría muy selecta, la cual en su mayoría era masculina. Para el siglo XVIII la educación de la mujer estaba orientada a las labores propias del hogar y a oficios manuales y algunas sabían leer y escribir pero por iniciativa propia.

Sin embargo, a finales del siglo XVIII en 1783, una mujer de excepcionales virtudes y profundo sentido de servicio social, María Gertrudis Clemencia de Caicedo y Vélez, viendo ella que

33 JARAMILLO, Nueva historia de Colombia. Op. Cit., p.66. 
el adelanto cultural no tenían mayor desarrollo, debido a la incomunicación con el exterior y por falta de maestras idóneas, la educación femenina ofrecía lamentables atrasos, solicitó la asesoría del Instituto de Nuestra Señora, de la Compañía de María, fundada por Santa Juana de Lestonnac y mediante cédula real del monarca Carlos III se aprobó finalmente la fundación del Monasterio Colegio de La Enseñanza, realizada el 23 de abril de 1783.

Eran los antecedentes de la educación de la mujer del Siglo XVIII, es por ello que Santander el 6 de octubre de 1820 dicta un decreto, mediante el cual se ordenaba la creación de escuelas para la enseñanza de las primeras letras en todas las villas, ciudades y lugares que tuvieran bienes propios y determinó que los conventos abrieran escuelas.

Con la misma preocupación Santander en 1821, en el Congreso de Cúcuta discute el tema relativo a la instrucción pública en el país, sin embargo no queda establecida en la constitución, sino que delega la función de regular el derecho a la educación al Congreso, es éste por medio de leyes el que reglamenta la instrucción pública y en agosto 2 de 1821 emite una ley que disponía que el poder ejecutivo hará que se funden escuelas de niñas en cabeceras de los cantones y demás parroquias en que fuere posible, pero el 6 de agosto del mismo año y el mismo congreso consideró: que en el estado actual de guerra y desolación de los pueblos es imposible que el gobierno de la República pueda proporcionar los fondos necesarios para escuelas de niñas y casa de educación para las jóvenes ${ }^{34}$; de la misma forma se estableció en la misma ley que era necesario que los conventos de religiosas abrieran escuelas o casas de educación para niñas, y se facultaran arzobis-

34 LONDOÑO VEGA, Patricia. Educación de la Mujer en la Joven República. http://www.lablaa.org/blaavirtual/publicacionesbanrep pos, obispos y prelados para que hicieran las dispensas necesarias con tal fin.

Sin estar conforme Santander en 1826 elabora un plan de estudios ${ }^{35}$ para reformar la educación, estableciendo que la enseñanza pública debe ser gratuita y común y establece escuelas de niñas en las cabeceras de los cantones y demás parroquias para que aprendieran a leer, escribir y ortografía, los principios de aritmética, los dogmas de la religión y la moral cristiana, los derechos y deberes del hombre en sociedad, pero además tenían que aprender costura.

La lucha de Santander se ve obstaculizada por unos años debido a que sube a la presidencia el Libertador - Simón Bolívar que dura en ella desde 1827 a 1830, donde su gobierno se centro en el establecimiento de la constitución Boliviana pero se disolvió la Gran Colombia y Santander es elegido para un segundo periodo desde 1832 hasta 1837. Para el año 1832 la educación de la mujer tuvo progreso y se creó el colegio de La Merced que seria el segundo establecimiento oficial para la enseñanza superior femenina. Era dirigido por señoras de alta cultura, que estaban asesoradas por pedagogos y el apoyo del gobierno. Las clases que se dictaban era la aritmética, geografía, ciencias físicas y naturales, lengua castellana y francesa, geometría, dibujo, música, principios de religión, moral, urbanidad y economía domestica. Para el año de 1835 había 146 escuelas que se dedicaban a la formación de niñas.

Gracias al apoyo estatal de fortalecimiento para la educación de la mujer, se comienza a gestar por medio de particulares escuelas para la enseñanza de las mujeres. Es así como Matilde Baños creó en Bogotá un establecimiento de carácter privado destinado a la educación

35 FOZ, Pilar. El siglo XIX, utopías y realidades. Una difícil centuria para la Enseñanza. Bogotá: Academia Colombiana de Historia. 1997. Pág. 243. 
de niñas pertenecientes a familias pudientes, enseñándoles a las alumnas escritura, lectura, trabajos manuales, geografía, aritmética, música y gramática francesa. De la misa forma la santafereña, Isabel Cárdenas, crea una escuela de educación de niñas entre los seis y los doce años, que permanecían allí internas. En Medellín, Petronila Caballero Pardo dirigió una escuela para niñas, en la cual enseñaban lectura, escritura, aritmética y geografía.

Con la salida de Santander de la presidencia y la llegada de Pedro Alcántara Herrán, se produce por parte del congreso una ley de instrucción primaria que discrimina las mujeres $^{36}$ y la reforma que trata de promover el Ministro Mariano Ospina Rodríguez de introducir en los planes de estudio tanto de las humanidades como las ciencias técnicas, se cae y sólo se admite para los planes de estudio de los hombres. El avance en la época de los cuarenta de la educación de la mujer fue por iniciativa privada, fue así como en Bogotá el señor Pedro José Diéguez, fundó en 1844 un colegio para mujeres, en el cual se enseñaba escritura, lectura, aritmética, castellano, ortografía, contabilidad, religión, geografía y francés; además, las señoritas aprendían trabajos manuales ayudadas por la directora, Manuela Mutis. De la misma forma Sixta Pontón y Piedrahíta, se empeñó en traer a Colombia a las religiosas francesas de la Sociedad del Sagrado Corazón, para educar niñas y jóvenes de la alta sociedad. Pero no lo logró y fundó la Asociación Piadosa del Sagrado Corazón, con el mismo fin. En este establecimiento se enseñaba ${ }^{37}$ religión, gramática castellana, aritmética, contabilidad, geometría, geografía, física, astronomía, historia, italiano, francés e inglés, moral, música y canto; las niñas debían aprender a bordar en lino, seda y oro; a pintar, a confeccionar flores, a remendar, a tejer.

$36 \quad$ FOZ, Op. Cit., p. 250.

37 LONDOÑO, Op. Cit.
A finales de la década de los cuarenta se crea en Medellín un colegio llamado Santa Teresa, creado y promovido por los padres de familia y con el apoyo del Gobernador, siendo el primer centro de enseñanza de secundaría para señoritas, se les enseñaba lectura, escritura, dibujo, costura, bordado, calado, matemáticas, gramática, geografía, moral, urbanidad y economía doméstica

El panorama de la educación de la mujer se ve favorecida con la reforma del 1870, estableciendo la educación de la mujer de era obligatoria, gratuita y neutra. En el año de 1872 se creo la primera normal femenina y fue así que la mujer pudo acceder a la cultura y a la educación superior.

Ser maestras les brindo a las mujeres la única ocupación de donde podía obtener beneficios económicos y un lugar en la sociedad. En el año de 1872 llego al país la comunidad de las religiosas de los Sagrados Corazones que fundaron un colegio. Luego llegaron las de la Presentación de Tours $^{38}$, para hacerse cargo de un hospital en Bogotá y abrieron un centro educativo.

A pesar que las mujeres si contaban con educación era un sistema que debía estar acorde a los modelos femeninos, por lo cual su educación también tenia que seguir unos parámetros para su desarrollo en el hogar, para que sea una persona útil en las labores de su casa y se entregue abnegadamente a la crianza de los hijos, que serán los futuros miembros de la sociedad ${ }^{39}$.

Transcurrida la época de la exclaustración y del retorno de los religiosos a sus posesiones, los jesuitas, conocedores del funcionamiento de las casas de Nuestra Señora en España y de sus colegios, aconsejaron a las Madres de

$38 \quad$ FOZ, Op. Cit., p. 271.

39 VAHOS VEGA, Luis Arturo. Mujer y educación en la Nueva Granada. Bogotá: Comunicación Creativa Ramírez Ltda. 2002. Pág. 185. 
la Enseñanza solicitar religiosas de las casas de España. La Madre Concepción Urrutia inició afanosamente los contactos, primero en Francia y luego en España, esfuerzo que fructificó cuando en 1893 la madre Mercedes Caro acudió a la casa de Barcelona de donde le enviaron tres religiosas, quienes impulsaron con fervor el futuro del proyecto ${ }^{40}$.

\section{CONCLUSIÓN}

La evolución del derecho a la educación en el periodo comprendido entre 1820 a 1876 desde la perspectiva constitucional, social y política, se puede diferenciar en tres etapas:

La primera etapa comprendida entre 1820 a 1849, la educación como derecho posee gran importancia, debido a su consagración constitucional, donde la educación goza de influencia por parte de la iglesia debido a la creencia y respeto que se tiene hacia esta institución. Igualmente se caracteriza este periodo por el establecimiento de la educación como pública, sin embargo es importante resaltar que la función de impartir enseñanza no era monopolio estatal, sino que podía estar en manos de particulares, claro que bajo la vigilancia y control del gobierno.

La segunda etapa comprende desde 1850 a 1869 , el derecho a la educación tuvo desarrollo gracias a decretos y leyes expedidos en la época. La explicación del avance legislativo se da porque la constitución delegó en el legislativo la función de reglamentar el derecho a la educación, pero es de vital importancia dejar en alto el sentimiento y la ideología tanto de Santader como de Mariano Ospina de impulsar este derecho. Es en esta época donde se evidencia la mayor creación de colegios, escuelas, normales y universidades y se la opción de la educación sin preferencias religiosas.

\footnotetext{
40 http://www.colegiodelaensenanza.edu.co/historia. php
}

Como última etapa 1870 a 1876, la educación se consagra de nuevo como un derecho constitucional, claro que su enseñanza ya no es exclusiva por directrices del estado, sino que existe una coadyuvancia entre el sector publico y el privado y se promueve la reforma de 1870 que no se pudo llevar a cabo por la influencia de la iglesia y la guerra civil.

De otro lado y con relación a la educación de la mujer, se debe de resaltar que mientras estuvieron vigentes los planes educativos de Santander, en los decenios de 1820 y de 1830 , la instrucción de la mujer fue amparada por la iniciativa privada.

Sin embargo con el proyecto del código educativo de 1834 se lograron importantes avances, como la instrucción de las mujeres no se circunscribió sólo aquellas labores propias de su sexo y se les permitió que aprendieran aritmética, lectura, escritura y gramática castellana, saberes que podían prepararlas para un futuro mejor tanto personal como para el manejo del núcleo familiar.

\section{BIBLIOGRAFÍA}

ARIZMENDI POSADA, Ignacio. Presidentes de Colombia 1810 - 1990. Bogotá: Planeta Colombia Editorial S.A. 1989.

BOHORQUEZ CASALLAS, Luis Antonio. La Evolución Educativa en Colombia. Bogotá: Publicaciones Cultural Colombiana, Ltda.

BUSHNELL, David. Colombia una Nación a pesar de sí misma - De los tiempos precolombinos a nuestros días. Bogotá: Planeta Colombiana Editorial S.A. 1996.

CANTOR REY, Ernesto. Las generaciones de los derechos humanos; editorial Ibañez; Bogotá; 2007.

FOZ, Pilar. El siglo XIX, utopías y realidades. Una difícil centuria para la Enseñanza. Bogotá: Academia Colombiana de Historia. 1997. 
GUILLÉN DE IRIARTE, María Clara. Los estudiantes del Colegio Mayor de Nuestra señora del Rosario. Bogotá: Editorial Universidad del Rosario, 2008.

JARAMILLO URIBE, Jaime. Nueva historia de Colombia. Bogotá: Planeta Colombia Editorial S.A. Vol. 2. 1989.

JARAMILLO URIBE, Jaime. Manual de Historia de Colombia. Colombia: Tercer Mundo Editores. 1999.

NIKKEN, Pedro. La garantía internacional de los derechos humanos. Venezuela: Editorial jurídica de Venezolana. 2006

SUESCÚN MONROY, Eduardo. Universidad Proceso histórico y jurídico. Bogotá: Editorial Grijalbo S.A. 1994.

TASCON, Tulio Enrique. Historia del Derecho Constitucional Colombiano. Bogotá. 2000.

VALENCIA VILLA, Hernando. Cartas de Batalla - Una crítica del constitucionalismo colombiano. Bogotá: Fondo Editorial CEREC. 1997.

VEGA DURAN, Alba Eugenia. Rasgos y vigencia del pensamiento educativo de Simón Bolívar. Bogotá: Universidad de la Sabana, 1981.

VAHOS VEGA, Luis Arturo. Mujer y educación en la Nueva Granada. Bogotá: Comunicación Creativa Ramírez Ltda. 2002.
YARCE, Jorge, LOPERA, Carlos Mario e PACHECO, Iván Francisco. La Educación Superior en Colombia. Bogotá: Instituto Internacional de la Unesco para la Educación Superior en América Latina y el Caribe, 2002.

YOUNES MORENO, Diego. Breve Historia del Derecho Constitucional Colombiano. Bogotá: Legis S.A. 1997.

\section{Tecnicas}

http://www.ivic.ve/memoria/bios/lancaster joseph.htm.

http://www.urosario.edu.co/FASE4/web visitantes/historia.htm.

http://www.unal.edu.co/documentos/creacion unal.pdf.

http://www.colegiodelaensenanza.edu.co/ historia.php

\section{Secundarias}

Constitución del 30 de agosto de 1821.

Constitución del 5 de Mayo de 1830.

Constitución del 1 de Marzo de 1832

Constitución de la República de Nueva Granada de 1853.

Constitución Política de los Estados Unidos de Colombia de 1863. 